\title{
$\underline{\text { SURFING OR DROWNING? STUDENT NURSES’ INTERNET SKILLS }}$
}

Carol S Bond. MSc BA(Hons) RGN

Senior Lecturer, Informatics for Health and Social Care

Institute of Health and Community Studies, Bournemouth University, Bournemouth House, Christchurch Road, Bournemouth, Dorset. BH1 1LH

Tel 01202504356

Fax 01202504398

cbond@bournemouth.ac.uk 


\begin{abstract}
$\underline{\text { ABSTRACT }}$
The ability to use the Internet is an essential skill for nursing students, both to support their studies, nursing students spending a lot of their time working away from the university campus, and to develop skills in using an increasingly essential tool for professionals. A study at Bournemouth University, England, found that new student nurses had poor internet skills, and were not frequent users prior to starting the course.

There was no link found between the students' age and their internet use or skills. A clear link was however found between ability and frequency of use, except in relationship to students' ability to conduct an effective search. Almost half of the respondents said that they find far too much irrelevant information when searching for information on the Internet.
\end{abstract}




\section{$\underline{\text { INTRODUCTION }}$}

The ability to use Information Technology (IT) effectively is an increasingly important skill for nursing students. It is essential to support their student experience, and also to give them the basics of the Informatics skills that they will need in practice once they are qualified nurses.

This study focuses on the skills in using the internet that nurses need, and those that they have at the start of their course. It reviews students' use of the Internet in the three months prior to starting a pre-registration nursing course, and investigates the students' perception of their skill levels when using internet based services.

\section{$\underline{\text { National Health Service Context }}$}

The UK National Health Service (NHS) is making effective working with information a high priority, having published its information strategy, Information for Health, in 1998. In 2001 they published further advice on the implementation of the strategy to compliment 'their other plans for developing the NHS, in Building the Information Core.

The aim of the various documents is to promote working with new information technologies to improve care for patients in several ways, including:

- Ensuring that professional staff have access to up to date information on which to base their practice.

- Speeding up, and easing, access to services for patients

- Improving communication flows of essential patient information

- Ensuring that patients and carers are informed about the NHS and best practice in relation to their condition

Nurses need to be able to understand the role of information within the organisations they work in, as well as its role in supporting their professional practice. Additionally, with more care taking place at locations other than hospitals, nurses need to be able to communicate electronically within their own organisation and across professional and organisational boundaries.

Information for patients is as important as information management and communications. Historically nurses have had a role as information gatekeepers, with most detailed health information only available in journals and health libraries, with access limited to professionals. With the widening availability of the internet much more information is now available, and access to it is easier. One implication of this is the ease of access to internet based information for nurses. They no longer have to visit the library to access information, or wait for the librarian to send information to them. If they have an Internet connection, and the skills to use it, they can access information anywhere, and at any time they need to. Another benefit is that their patients can now also access this information without going through a professional gatekeeper, this means that all nurses need to be able to help patients evaluate the information they have found, and direct them to reliable internet sources. 
The Nursing and Midwifery Council (NMC), which registers all practicing nurses in the UK, requires all nurses entering the register to demonstrate the skills needed to record, store, retrieve, and organise data essential for care delivery.

The Quality Assurance Agency for Higher Education in the UK (QAA) have introduced benchmarks, which 'describe the attributes, skills and capabilities that a graduate with an honours degree in a specific subject might be expected to have' (QAA 2003). The benchmarks for nursing identify that not only should nurses be competent in using common software packages including word processing, email, spreadsheets and databases but that they should be able to access health care research and literature databases; use the internet as an information source; and use computerised patient information systems. They should also understand the associated issues of data integrity and security and patient confidentiality.

\section{$\underline{\text { Educational Context }}$}

There is an active debate around what is being aimed for when teaching nursing students IT skills. It is variously described as computer literacy (Saranto \& Leino-Kilpi 1997 and Patrikas 1999); Information literacy (Wallace at al 1999 and Shorten et al 2001); Electronic literacy (Topping \& McKenna 1999) and even Technical literacy (Charp 1999). All of these terms are however used as different descriptions for a very similar concept, that of having the skills to use information and technology to support professional practice. The author has no desire to become mired in discussing the terminology, and will suffice to use the simple term of IT skills to encompass this broad concept.

That these skills are needed is becoming a universal truth for nurses working in many countries. Drucker (1994) is of the opinion that in the future anyone who wishes to be considered educated will be someone who has embraced the notion of lifelong learning. The ability to use a computer, and effectively find and use the wealth of information that it enables access to, is becoming an essential tool for anyone who wishes to progress in education and in a professional career.

The increased access to information that is afforded by computers is affecting all areas of peoples lives, both at work and at home. Dolence \& Norris, $(1995, \mathrm{p} 2)$ are of the view that 'Society is undergoing a fundamental transformation from the Industrial Age to the Information age'. IHCS needs therefore to equip its nursing students with the skills and knowledge to work within this new paradigm.

\section{$\underline{\text { THE STUDY }}$}

\section{Method}

It was decided to carry out this research undertaking a questionnaire based survey of students commencing pre-registration nursing courses in the 2000-2001 academic year. The aim of the questionnaire was to investigate the use that students had made of the internet in the 3 months prior to starting the course; their perceptions of their skill levels, and their views on their ability to carry out some basic tasks:

Enter a web address in a browser

Send and receive emails 
Some demographic information was also collected, and students were asked about their computer ownership, and if they had an Internet connection. They were then asked to rate their skills in using the WWW, with the categories of 'excellent', 'good', 'basic' and 'not used' being offered. Rather than relying on students perceptions of what constituted each skill level being consistent across the group, and with the teaching teams ideas of skill levels, students were asked to say if they could complete some basic tasks without any problems. Whilst it was accepted that the definition of what constitutes a problem is subjective, this was left to the students to interpret as they felt appropriate.

The tasks, Enter a web address in a browser; Use a search engine to find information on the WWW and Send and receive emails were chosen after discussion within the teaching team, and with reference to external standards, including the European Computer Driving Licence (ECDL) and CLAIT, both basic IT qualifications in wide use in the UK.

In the final section of the questionnaire 3 statements were offered, and using a likert type scale students were asked to indicate their agreement, or otherwise with statements including:

I often use email to communicate with friends

I end up with far too much irrelevant information when I try to find things on the Internet

I enjoy surfing the WWW

The questionnaire was distributed to students in their first, introductory, lecture during freshers week. It was self-administered, with the author available to answer any queries that the students had. This method of distributing and collecting questionnaires has been identified by Oppenheim (1992) as having a high response rate. This was also found to be true for this survey. Of the 377 students commencing the course during the academic year 334 completed the questionnaire, a response rate of $89 \%$.

The results were entered into the SPSS software package for analysis. As the data was nominal or ordinal it was analysed using non-parametric methods. Cross-tabulations were used to look for relationships between the variables, and Chi-square used to calculate the statistical significance of the results.

\section{$\underline{\text { RESULTS }}$}

Computer ownership amongst the group was quite high, with $45 \%$ having a computer all year round, and a further 33\% having a computer at their holiday address. Of the students with a computer $72 \%$ had an Internet connection. Actual use of the WWW in the three months prior to starting the course was much lower than the ability to connect the Internet, with only 34\% using it at least weekly. About the same number (35\%) hadn't used it at all in that period. The amount of email use was very similar, with $34 \%$ using it at least weekly and 37\% not at all. Students were asked about their age and gender, $88 \%$ of respondents were female, ages were grouped, $60 \%$ were aged $18-25$, $23 \%$ aged $26-35$, and $17 \%$ over 35 . 
Students did not report a high level of confidence in their WWW skills, nearly half (49\%) thought their skills were basic, and a further 23\% said they had never used the WWW. Only 3\% considered themselves to be expert.

Self reported skill levels did not always correspond to the tasks that students could carry out competently. Whilst overall 52\% said that they could enter a web address into their browser software, a task considered as basic by the teaching team, $13 \%$ of those students who rated their skill levels as excellent or good, and $44 \%$ of those who considered their skills to be basic responded that they could not do this without problems $(\mathrm{p}<0.01)$. A similar result was found when students were asked about their ability to use a search engine without problems. The number of expert or good users who could not do this was lower at $3 \%$, however $44 \%$ of those who thought their skills were basic couldn't use a search engine without problems $(\mathrm{p}<0.01)$.

Student weren't asked to rate their skills in using email, but in response to a question about their ability send and receive emails without problems $46 \%$ said that they couldn't do so.

In responding to statements given students were had the option of strongly agreeing, agreeing, disagreeing or strongly disagreeing. There was also an option for people who hadn't ever used the WWW or email. 48\% of respondents indicated agreement with the statement 'I end up with far too much irrelevant information when I try to find things on the Internet' with 18\% agreeing strongly. 20\% said that they had never tried. In response to the statement 'I enjoy surfing the WWW' 56\% agreed to some extent with the statement, with $24 \%$ strongly agreeing. Fewer (41\%) responded positively to the statement 'I often use email to communicate with friends' with $32 \%$, saying they had never used email.

There is a popular belief that older people have poorer computer skills than younger people. This was not found to be the case in this study. No statistically significant difference was found in the ability to carry out tasks, or in responses to the statements offered, and the students' age.

The main determinant of students skill levels was the amount that they used the WWW and email. Statistically significant results $(p<0.01)$ were found in cross-tabulations of frequency of use, and ability to carry out tasks. Chart 2 (below) shows the relationship between frequency of recent Internet use and the ability to enter a web address into a browser. 
Enter Web Address without problems?

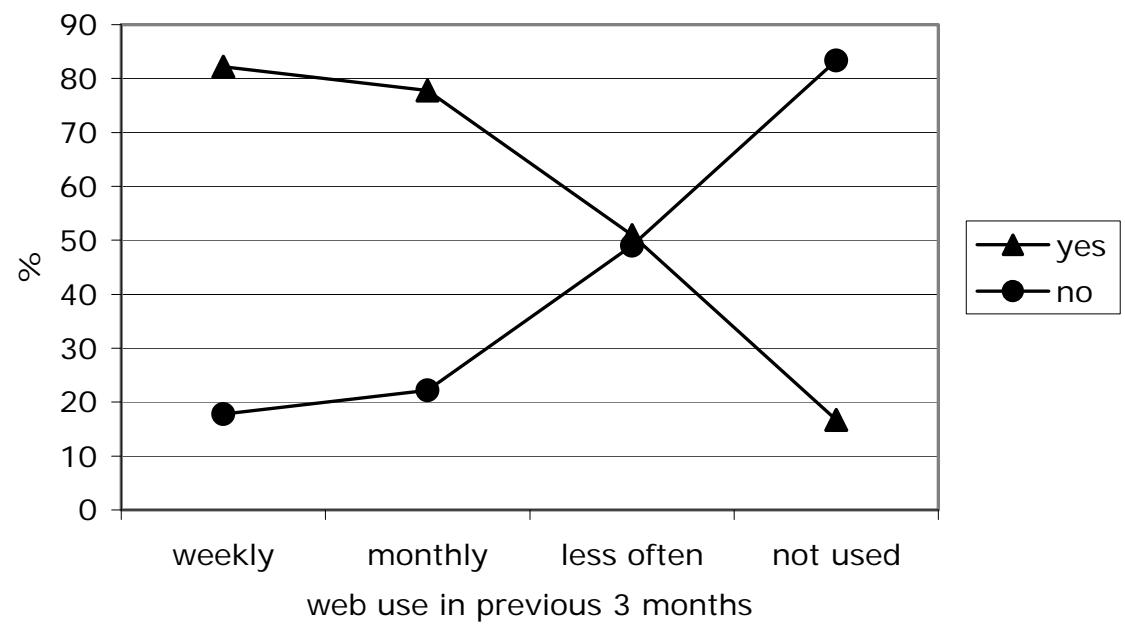

Chart 2. Ability to enter web addresses and frequency of use of the Internet

The relationship between frequency of email use and ability to send and receive emails is shown in chart 3 overleaf.

Send \& receive email without problems?

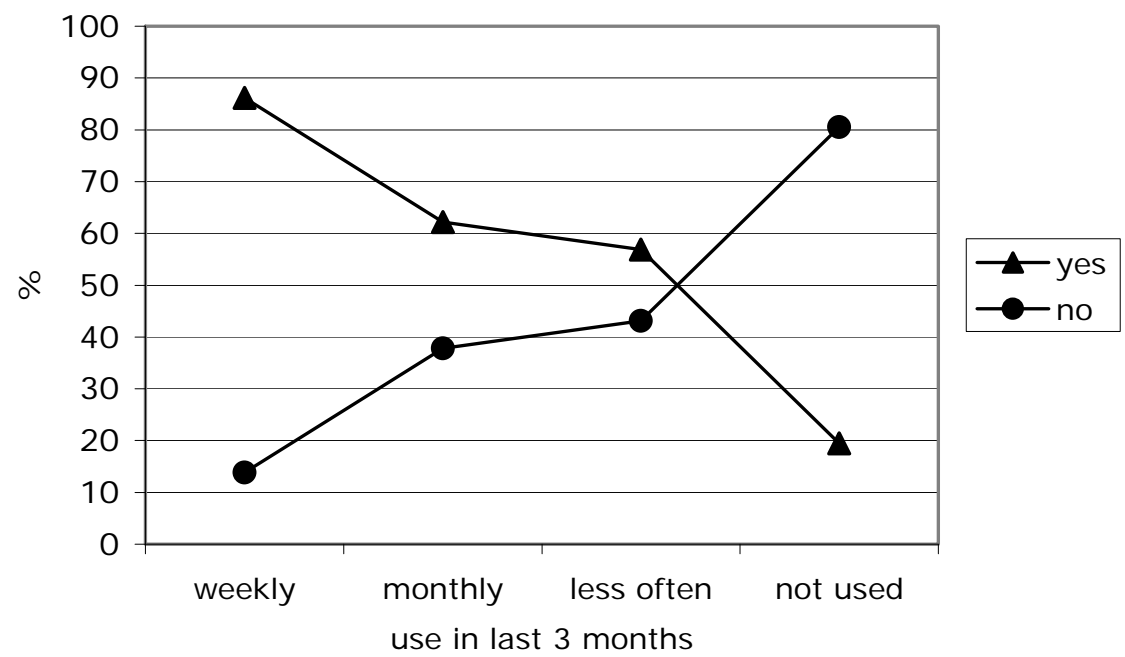

Chart 3. Ability to send and receive email and frequency of use

The only exception to this relationship was in response to the statement 'I end up with far too much irrelevant information when I try to find things on the Internet' where only $33 \%$ of respondents disagreed with the statement, whatever their usage levels.

\section{CONCLUSION}

The picture gained from the results of this research is that the majority of students are not using the Internet to any great extent prior to starting the course, and that their ability to carry out a range of basic tasks is equally low. An interesting finding that merits further investigation is the students' perception of their skill levels. All the tasks 
students were questioned about are skills covered in basic level IT qualifications, such as the European Computer Driving Licence. The results however show that a significant proportion of students who thought their skills were good or excellent said that they could not carry the task out without problems, raising the question of how they reach their assessment of their skill levels.

The age of the students has not been found to be a determinant of computer use or ability. Possibly not surprisingly the students who make the most use of the Internet report higher skill levels than those who do not use it as frequently, although irrespective of experience, students tend to have problems with effective searching to find relevant information on the Internet.

As the UK government is seeking to increase the number of students entering nursing changing the recruitment policy to only take students who already have good IT skills is not an option. The solution adopted has therefore been to develop an Introduction to Health Informatics programme, delivered throughout the first year of the course. This develops the not only the students computer skills, but also their understanding of the use of computers in both their student and professional roles.

A large part of the programme is focused on developing skills to use a variety of Internet services, including email which is used as the main communication channel with the students, and the WWW, both for accessing professional information, and as a learning and teaching tool. 


\section{REFERENCES}

Charp, S. 1999. Technical Literacy - where are we?. T H E Journal 27 (3) pp6-8

Drucker, P. 1994. The Age of Social Transformation. The Atlantic Monthly (Nov) pp53-80

Dolence, M \& Norris, D. 1995. Transforming Higher Education: A Vision for Learning in the 21st Century. Ann Arbor, MI: Society for College and University Planning (SCUP).

Oppenheim, A. 1992. Questionnaire Design, Interviewing and Attitude Measurement. Pinter Publishing Ltd, London.

Patrikas, E. 1999. Computer Literacy. T H E Journal 27 (5) pp60-65

Saranto, K \& Leino-Kilpi. 1997 Computer literacy in nursing: developing the information technology syllabus in nursing education. Journal of Advanced Nursing 25 pp377-385

Shorten, A. Wallace, M \& Crookes, P. 2001 Developing information literacy: a key to evidence-based nursing. International Nursing Review 48 pp86-92 International Council of Nurses.

Topping, K \& McKenna, M. 1999. Introduction to Electronic Literacy part 1. Reading \& Writing Quarterly. 15 (2) pp107 - 111

QAA. Understanding courses: Benchmark statements and programme specifications. http://www.qaa.ac.uk/crntwork/students/understandcourses.htm accessed online $18 / 03 / 2003$ 